\title{
Female reproductive output in a Mediterranean bottlenose dolphin Tursiops truncatus population
}

\author{
Monica Francesca Blasi ${ }^{1, *, \#}$, Chiara Bruno ${ }^{1, \#}$, Luigi Boitani ${ }^{2}$ \\ ${ }^{1}$ Filicudi WildLife Conservation, Stimpagnato Filicudi, 98055 Lipari (ME), Italy \\ ${ }^{2}$ Department of Biology and Biotechnologies, University 'La Sapienza', Viale dell'Università 32, 00185 Rome, Italy
}

\begin{abstract}
The reproductive output of wild bottlenose dolphins Tursiops truncatus has extensively been investigated; nevertheless, it remains widely unexplored in the Mediterranean Sea. We investigated the reproductive history of female bottlenose dolphins in the Aeolian Archipelago (Italy). Thirteen years of photo-identification data were used to track the reproductive pattern of 7 females and their 16 calves. The birth period was accurately estimated within 1 mo for 6 calves (37.5\%), peaking in June/July. The mean number of calves for females was $2.3 \pm 1.1$ (SD), ranging from 1 to 4 . The mean interbirth interval was $3.5 \pm 1.6 \mathrm{yr}$, ranging from 2 to $7 \mathrm{yr}$. The mean weaning age was $3.2 \pm 0.6 \mathrm{yr}$, although 1 calf may have been weaned as late as its fifth birthday. Mother-calf postweaning associations were tracked for 9 calves and ranged from 4 to $10 \mathrm{yr}$ of residence in the maternal group of the calf. The age of first pregnancy was $7.5 \mathrm{yr}$. The number of calves was influenced by the mean maternal group size, with females that were sighted in larger groups having more calves. However, the number of calves was not influenced by the strength of the associations of mothers with other females. Calf mortality by age 1 was high $(12.5 \%)$. Two juveniles also died postweaning within 6 yr of their birth. Finally, 2 females may have died during the study, as they were not re-sighted at the end of the study. Our results highlight the need to implement urgent conservation actions to protect this bottlenose dolphin population.
\end{abstract}

KEY WORDS: Birth period $\cdot$ Interbirth interval $\cdot$ Weaning age $\cdot$ Permanence time $\cdot$ Calf mortality Aeolian Archipelago · Bottlenose dolphin

\section{INTRODUCTION}

The reproductive output of wild bottlenose dolphins Tursiops truncatus has been extensively explored worldwide (Fruet et al. 2015, Rossi et al. 2017, Baker et al. 2018), especially for resident populations inhabiting estuary areas of sub-tropical regions (Shane et al. 1986, Steiner \& Bossley 2008, Bezamat et al. 2020); however, it remains largely undocumented in the Mediterranean Sea, where bottlenose dolphins have been studied only in relatively small areas (Gol'din \& Gladilina 2015, Rossi et al. 2017). Bottlenose dolphins live in fission-fusion societies characterized by extensive maternal investment, with prolonged mother-infant relationships and juveniles occasionally associating with their mothers post-

*Corresponding author: blasimf@yahoo.com

\#These authors contributed equally to this work weaning (Oftedal 1997, Mann \& Smuts 1998). Common reproductive trends have been identified among different bottlenose dolphin populations (Henderson et al. 2014, Brough et al. 2016), but some reproductive parameters, such as seasonality of births (Urian et al. 1996, Mann et al. 2000, Thayer et al. 2003, Karniski et al. 2018), weaning period (Tavolga 1966, Cockcroft \& Ross 1990, Mann \& Smuts 1998), and age of first reproduction (which may vary between 7 and $12 \mathrm{yr}$ for bottlenose dolphins, depending on region), may vary greatly among populations (Wells et al. 1987, Schroeder 1990, Kasuya et al. 1997) as a result of ecological and social factors, e.g. group size, protection from predators/conspecifics, and mate choice (Mann et al. 2000, Krzyszczyk et al. 2017).

(C) The authors 2020. Open Access under Creative Commons by Attribution Licence. Use, distribution and reproduction are unrestricted. Authors and original publication must be credited. 
Photo-identification (photo-ID) is a technique which uses scarring patterns and unique nicks on the dorsal fins of individuals to investigate the ecology and behaviour of dolphins (Würsig \& Jefferson 1990). Several studies have applied photo-ID methods to investigate demographic and reproductive factors in wild bottlenose dolphin populations (Grellier et al. 2003, Robinson et al. 2017, Bezamat et al. 2020). Hammond et al. (1990) used the individual reproductive history of repeatedly sighted females over multiple years to assess various parameters, such as age at first reproduction, birth season, birth intervals, and productivity. The description of reproductive patterns over time is possible using such data, which enables investigations on the variation in reproductive rates within threatened areas, where dolphin studies are often lacking.

In recent years, a reduction of $30 \%$ was recorded in the number of bottlenose dolphins inhabiting the Mediterranean Sea (Bearzi et al. 2009), largely as a consequence of deliberate killing, habitat degradation, and overfishing (Reeves \& Notarbartolo di Sciara 2006). This suggests that the reproductive output of bottlenose dolphins might be largely influenced by the nature and extent of these threats in different regions (Bearzi et al. 2008, Reeves \& Notarbartolo di Sciara 2006, Gnone et al. 2011). Assessing female reproduction in Mediterranean bottlenose dolphins is of paramount importance to identify the viability of the population and formulate adequate conservation measures (Caswell 2001, Fujiwara \& Caswell 2001).

A 13 yr (2005-2017) photo-ID study of bottlenose dolphins in the Aeolian Archipelago, in the Southern Tyrrhenian Sea (Italy), has revealed complex societies and behaviours adapted to both environmental and anthropogenic conditions (Blasi \& Boitani 2012, 2015, Blasi \& Boitani 2014). The encounter rate of dolphins has decreased significantly in recent years, with data suggesting that Aeolian bottlenose dolphins have high site fidelity to the area (Blasi \& Boitani 2012, 2015, Leone et al. 2019). Beginning in spring-summer, females show strong associations with their calves, spending extensive time in the safest areas for feeding, socializing, resting, and caring for their calves (Blasi \& Boitani 2012, 2014, Blasi et al. 2015). In contrast, males adapt their behaviour to achieve the highest probability of locating and capturing prey in fishing areas (Blasi \& Boitani 2012, 2014, Blasi et al. 2015). In particular, some males have specialized to aggregate in small groups to depredate gillnets (Blasi \& Boitani 2012, 2014, Blasi et al. 2015). Overfishing is high, and a marine protected area has not yet been implemented in the
Aeolian Archipelago, suggesting that food resources might be scarce for the dolphins (Blasi \& Boitani 2012, 2014, Blasi et al. 2015). A recent paper also showed that the Aeolian bottlenose dolphins are strongly malnourished and present skin lesions, such as gunshot wounds and mutilations (Leone et al. 2019).

In this study, data from a long-term mark-recapture study were used to document the reproductive history of female bottlenose dolphins living in the Aeolian Archipelago. Using high-quality dorsal fin photographs, the reproductive patterns of individual females and their calves were tracked to estimate the birth period, calf productivity, interbirth intervals, age of first reproduction, calf mortality, weaning period, group size, mother-calf postweaning associations, and association patterns among females.

\section{MATERIALS AND METHODS}

\subsection{Survey and photo-ID data}

The Aeolian Archipelago is located in the Southern Tyrrhenian Sea, north of Sicily, Italy $\left(38^{\circ} 35^{\prime} \mathrm{N}\right.$, $\left.14^{\circ} 34^{\prime} \mathrm{E}\right)$. Dedicated boat surveys were performed from June to September throughout 2005-2017 using random transects within a study area of $400 \mathrm{~km}^{2}$ (Blasi \& Boitani 2012, Blasi et al. 2015, Leone et al. 2019). Bottlenose dolphins were observed using a combination of focal group observations (Shane 1990), with instantaneous data sampling (Altmann 1974), and photo-ID techniques (Würsig \& Würsig 1977, 1979, Würsig \& Jefferson 1990). Assuming that clustered animals were also interacting (Whitehead \& Dufault 1999), associations were defined by membership to the same group, i.e. animals photographed in the same group and moving in the same general direction, interacting or engaged in similar activities, were considered to be associated (Shane et al. 1986). The focal group was defined as individuals within $10 \mathrm{~m}$ of at least 1 other dolphin in the group. When more than 1 focal group was encountered in the same survey, each sub-group was recorded as an independent sighting (Mann 1999). In the event that a group split up, 1 of the sub-groups was followed at random and independent of group size or activity (Mann 1999).

Each individual was photographed by standard photo-ID techniques. When possible, videos taken during each sighting were used for sex identification (Blasi \& Boitani 2014, Blasi et al. 2015), and individuals were identified by the natural markings on the 
body, especially on the dorsal fin. High-resolution photographs of distinctive dorsal fins were used to match individuals with a photo-ID catalogue of known individuals (Würsig \& Würsig 1977). Each dolphin in the catalogue was classified with a code (PHD) followed by a number (n) according to its photo-identification date (PHDn). In addition, each calf was classified with the code of the mother followed by the number of offspring produced by the female since the start of the study (i.e. PHDn[m]). For example, the third calf of female PHD9 was classified as PHD9[3], while PHD9[1][1] is the calf of calf PHD9[1] who became a mother in the study period. The mean $( \pm \mathrm{SD})$ number of calves for reproductive females was also estimated.

\subsection{Age and sex}

Each year, all individuals were classified according to their relative size assessed through photo-ID (Blasi \& Boitani 2012, 2014, Leone et al. 2019): (1) adults: large and robust animals, with dark skin colour and many marks on the dorsal fin and body, and often accompanied by a calf; (2) juveniles: less robust individuals at least two-thirds the length of adults, usually with less distinctive nicks, or without nicks in their dorsal fins and not associated with an adult; and (3) calves: one-third the size of adults, in close association with an adult and usually without nicks in their dorsal fins. Calves were also identified according to typical surfacing behaviour, swimming in infant position, in contact underneath the mother, or spending all of their time with an adult (Grellier et al. 2003).

Dolphin sex was determined by opportunistic viewing of the genital region and later confirmed by pictures and frame shots of the genital slit taken during each sighting. In this study, it was possible to collect several pictures of each individual, which helped in sex determination. Adult bottlenose dolphins lack obvious and detectable sexual dimorphism (Read et al. 1993), and it is not always easy to obtain good quality pictures of the genital area for sex determination (Connor et al. 2000). Reproductively mature females (Grellier 2000) were identified when they maintained a close and lasting ( $>2 \mathrm{yr}$, and in all sightings for each year) relationship with a calf, which was presumed to be their offspring. Based on long-term photo-ID data, all calves analysed in our study were strongly associated with known females identified by their dorsal fin. It is well known that alloparental care could lead to false mother-calf pairings in bottlenose dolphins (Whitehead 1996), but this potential error was re- moved by ensuring at least 2 photographic frames from the same sighting and more than 2 frames within the same season showing the calf in echelon position with the presumed mother.

\subsection{Occurrence and group size}

The occurrence $(\%)$ for years (number of female sightings/years of sightings) and the occurrence (\%) for sightings (number of female sightings/total number of sightings) were calculated for each individual.

The group size of females was visually determined in situ and later verified by standard photo-ID techniques and videos taken during each sighting. The mean $( \pm \mathrm{SD})$ group size was calculated for each female on pooled sightings for the entire study period (Blasi \& Boitani 2014). A linear regression analysis (PAST 4 Software version 4.03) (Hammer et al. 2001) was used to examine the correlation between mean group size and the number of calves for females.

\subsection{Birth period}

The birth period was estimated based on (1) the time between the last sighting of the mother before giving birth and the sighting of the mother with a calf and (2) the proportional body length between mother and calf (i.e. calves less than $1 \mathrm{yr}$ old were about onethird of the length of the mother). The birth period was estimated to within 1 mo for all calves up to $2 \mathrm{yr}$ of age sighted before the end of the weaning period.

\subsection{Interbirth interval}

The years between the estimated birth period of a surviving calf and a subsequent birth were used to determine the interbirth intervals for each female dolphin. In order to reduce the probability that the birth of a new calf was missed for the less frequently sighted females, and the chance of the interbirth interval being shorter if mothers lost unsighted calves, the interbirth interval was calculated only for females that were adults in the first year of the project and were sighted for at least 9 years within the study period and more than 5 times each year. Finally, only females with a surviving calf of known birth within $1 \mathrm{yr}$, which did not disappear during the interbirth interval for more than $1 \mathrm{yr}$ from the study area, were included in the interbirth interval analysis. 


\subsection{Weaning period}

The weaning period was estimated based on the time between the birth period and the last sighting of the calf nursing (i.e. beak to the mammary slit). Since not all calves were observed nursing during the study period, the weaning period was also calculated based on the last sighting of the calf in infant position (Mann \& Smuts 1998). If the year of birth could not be determined, the calf was not included in the age-specific weaning period estimation. When a new calf was born, the weaning period for the old calf was estimated based on the last sighting at which the calf stopped its exclusive association with the new mother-calf pair (but not necessarily in infant position) and with the maternal group during the same year/season. A weaning period of $<6 \mathrm{yr}$ was fixed to provide a threshold value of assurance that the old calf had stopped nursing following the birth of a new one (Mann et al. 2000, Foroughirad \& Mann 2013, Karniski et al. 2018).

\subsection{Mother-calf associations postweaning}

Postweaning mother-calf associations were estimated from the last sighting at which a calf was exclusively with the maternal group until it was sighted in other dolphin aggregations, in the same year/season. It was possible to keep track of juveniles/adults only for calves that had distinctive dorsal fin markings before the end of the weaning period. In particular, postweaning mother-calf associations were estimated only for calves that were confirmed to be out of the weaning period, i.e. they were no longer nursing, swimming in infant position, or showing exclusive mother-new calf associations. For the estimation of the postweaning period, the sample size varied according to known birthdates, weaning dates, and survivorship of the calves. Furthermore, calves with an unknown birth period within $1 \mathrm{yr}$ were not included in the calculation of mother-calf postweaning associations. For each calf, the residence time with the mother was calculated as the sum of the weaning period and the postweaning period.

\subsection{Calf mortality}

The death by calf age (calf mortality) was also estimated for each adult female. In order to reduce the probability that the death of a calf was not recorded as a result of rare sightings of the mother, calf mortality was calculated only for females that were observed for at least 9 years within the study period, more than 5 times each year, and had not disappeared from the study area for more than $1 \mathrm{yr}$. Moreover, only calves with a known birth period within 1 yr were included in calf mortality analyses to ensure that unsighted calves had been weaned rather than presumed to have died. Specifically, for calves less than 2 yr old (i.e. an arbitrary time to assure exclusive mother-calf associations within the weaning period), if mothers were sighted repeatedly without the calf during the same year/season, it was assumed that the calf had died. Calf mortality was also estimated postweaning (i.e. more than 2 yr) for calves that had distinctive dorsal fins before the end of the weaning period, using the last date on which the calf was sighted in the study area (i.e. disappearing from the study area for more than 2 consecutive years).

\subsection{Female-female association patterns}

The half-weight index (HWI) was calculated by the equation $2 \mathrm{~N} /\left(\mathrm{N}_{\mathrm{PHD} 1}+\mathrm{N}_{\mathrm{PHD} 2}\right)$, where $\mathrm{N}$ is the number of times that individuals PHD1 and PHD2 were seen together, and $\mathrm{N}_{\text {PHD1 }}$ and $\mathrm{N}_{\mathrm{PHD} 2}$ are the total number of sightings of each individual (Cairns \& Schwager 1987, Bräger et al. 1994, Ansmann et al. 2012). To ensure the independence of sampling and avoid serial autocorrelation of sightings, only the first sighting was used when an individual dolphin was sighted more than once in a day (Bëjder et al. 1998). Pooled HWIs (years combined from 2005 to 2017) were calculated for pairs of females, juveniles, and calves that were well-marked and recaptured more than 6 times during the study period. Only calves sighted for more than 3 consecutive years and with complete known histories were included in the analysis due to the bias of their unique dependent relationships with their mothers. Group membership samples were used to obtain an association matrix of all individuals (Whitehead \& Dufault 1999). A PCA was applied to the HWIs to investigate whether association patterns differed significantly among females and their calves. Independent principal components (factors) were extracted from the original variables, from which the leading ones (i.e. those which explained more than $80 \%$ of variance) were plotted to identify significant association patterns (Blasi \& Boitani 2014). Finally, a simple linear regression analysis was used to investigate the correlation between the HWIs and the number of calves for each female 
(Blasi \& Boitani 2014). PAST 4 Software (version 4.03) was used to examine these relationships (Hammer e al. 2001).

\section{RESULTS}

We photo-identified 42 dolphins by the permanent marks on their dorsal fins during 272 focal follows between 2005 and 2017, i.e. 19 adult dolphins at their first sighting and 24 adults at their last sighting. Analysis of photographs of the genital area definitively identified 8 females and 14 males. By the end of the study, $80 \%$ of adults were classified as having high site fidelity, including 8 females, 14 males, and 2 individuals of unidentified sex. These dolphins were sighted at least 9 years of the study period, more than 5 times in the same year, and they never disappeared from the study area for more than $1 \mathrm{yr}$ (Table 1).

Only 7 females were clearly associated with a calf during the study period (Table 1), and a total of 16 calves were photo-identified in strong association with the mother (Table 2). The number of calf sightings varied from 2 to 57 within the study period (Table 2). The mean number of calves for reproductive females was $2.3 \pm 1.1$ (SD) and varied from 1 to 4 calves per female during the study period (Table 1). PHD4 was the most reproductive female with a total of 4 calves, followed by PHD9 and PHD10 with 3 calves each (Table 1). Four females (PHD3, PHD4, PHD9, and PHD10; $57.1 \%$ of females) disappeared from the study area $1 \mathrm{yr}$ before having a calf, to return the following year with a newborn (Fig. 1). However, 2 females were not sighted in the last years of the project (Fig. 1).

\subsection{Occurrence and group size}

Females PHD3 and PHD4 were observed more frequently than other females in the study area (Table 1). The mean group size of females (Table 1) varied from $4.5 \pm 2.9(\mathrm{SD})$ for PHD21 $(88.8 \%)$ to $6.8 \pm$ 0.8 for PHD9[1] (89.3\%). Furthermore, the number of calves appeared to be influenced by the mean group size of the mother, with females sighted in larger groups producing more calves $\left(\mathrm{n}=6 ; \mathrm{R}^{2}=0.7, \mathrm{p}<\right.$ 0.05) (Table 1).

\subsection{Birth period}

Our sample for the estimation of the birth period included birth age estimates accurate to within 1 mo for 6 calves $(37.5 \%)$, within 1 yr for 8 calves $(50 \%)$, and within 2 yr for 2 calves (12.5\%) (Table 2). The birth period was seasonal (spring-summer), peaking in June/July (Table 2).

\subsection{Interbirth interval}

One of the females (PHD6) sighted for at least 9 years, more than 5 times per year, and identified as an adult in the first year of the study was sighted with only 1 calf during the study period and, consequently, it was not included in the interbirth interval calculation (Fig. 1). Two females, PHD3 and PHD5, had a time gap between the weaning of a calf and the birth of another, such that pregnancy and/or loss could have occurred, while the others had a weaning period that overlapped with the birth of the new calf (Fig. 1). Consequently, the mean interbirth interval

Table 1. For each female bottlenose dolphin, the ID code, age at first and last sighting, occurrence (for years = number of female sightings/years of sightings, $\mathrm{n}=13$; for sightings = number of female sightings/total number of sightings, $\mathrm{n}=272$ ), mean \pm SD group size (GS) and \% of sightings with $>5$ individuals, mean \pm SD half-weight index (HWI), and number of calves are reported. A: adult; J: juvenile

\begin{tabular}{|c|c|c|c|c|c|c|c|}
\hline \multirow[t]{2}{*}{ ID } & \multicolumn{2}{|c|}{ - Age -} & \multicolumn{2}{|c|}{ - Occurrence $(\%)-$} & \multirow[t]{2}{*}{ Mean GS $(\%>5)$} & \multirow[t]{2}{*}{ Mean HWI } & \multirow[t]{2}{*}{ No. of calves } \\
\hline & First & Last & For years & For sightings & & & \\
\hline PHD3 & A & $\mathrm{A}$ & 92.3 & 39.5 & $5.3 \pm 2.7(76.9)$ & $0.49 \pm 0.23$ & 2 \\
\hline PHD4 & A & A & 76.9 & 30.2 & $5.7 \pm 2.8(70.8)$ & $0.43 \pm 0.22$ & 4 \\
\hline PHD5 & A & $\mathrm{A}$ & 61.5 & 16.9 & $5.2 \pm 2.6(77.3)$ & $0.45 \pm 0.22$ & 2 \\
\hline PHD6 & A & A & 38.5 & 12.8 & $5.3 \pm 2.6(90.9)$ & $0.49 \pm 0.24$ & 1 \\
\hline PHD9 & $\mathrm{A}$ & $\mathrm{A}$ & 53.9 & 16.3 & $5.2 \pm 3.1(77.3)$ & $0.25 \pm 0.27$ & 3 \\
\hline PHD9[1] & $\mathrm{J}$ & $\mathrm{A}$ & 23.1 & 2.9 & $6.8 \pm 0.8(89.3)$ & $0.27 \pm 0.31$ & 1 \\
\hline PHD10 & A & $\mathrm{A}$ & 69.2 & 21.5 & $5.6 \pm 3.1(61.1)$ & $0.36 \pm 0.26$ & 3 \\
\hline PHD21 & $\mathrm{A}$ & $\mathrm{A}$ & 38.5 & 7.6 & $4.5 \pm 2.9(88.8)$ & $0.26 \pm 0.28$ & 0 \\
\hline
\end{tabular}


Table 2. For each bottlenose dolphin calf, the ID code, sex, age at first and last sighting, occurrence (for years = number of calf sightings/years of sightings, $\mathrm{n}=13$; for sightings = number of calf sightings/total number of sightings, $\mathrm{n}=272$ ), years of occurrence (and number of years the calf was sighted), and estimated birth period are reported. The birth period was precisely estimated for 6 calves, while for the others the birth period was estimated within year 1 or 2 yr. UN: unknown; C: calf; $\mathrm{J}$ : juvenile; A: adult. Dates are given as d/mo/yr

\begin{tabular}{|c|c|c|c|c|c|c|c|}
\hline \multirow[t]{2}{*}{ ID } & \multirow[t]{2}{*}{ Sex } & \multicolumn{2}{|c|}{- Age -} & \multicolumn{2}{|c|}{ - Occurrence $(\%)-$} & \multirow{2}{*}{$\begin{array}{c}\text { Years of } \\
\text { occurrence (n) }\end{array}$} & \multirow[t]{2}{*}{ Birth period } \\
\hline & & First & Last & For years & For sightings & & \\
\hline PHD3[1] & UN & C & C & 7.7 & 1.6 & $2005(1)$ & $19 / 06 / 2005-26 / 06 / 2005$ \\
\hline $\mathrm{PH} 03[2]$ & UN & $\mathrm{C}$ & $\mathrm{J}$ & 38.5 & 21.5 & 2013-2017 (5) & $2012-22 / 04 / 2013$ \\
\hline PHD4[1] & UN & $\mathrm{J}$ & $\mathrm{J}$ & 23.1 & 5.2 & 2007-2009 (3) & 2006 \\
\hline PHD4[2] & UN & $\mathrm{C}$ & $\mathrm{C}$ & 30.8 & 2.9 & 2008-2011 (4) & 29/06/2008 \\
\hline PHD4[3] & UN & $\mathrm{C}$ & $\mathrm{J}$ & 38.5 & 8.1 & 2011-2017 (5) & $2010-02 / 06 / 2011$ \\
\hline PHD4[4] & UN & $\mathrm{C}$ & $\mathrm{J}$ & 30.8 & 12.8 & 2014-2017 (4) & 20/05/2013-2014 \\
\hline PHD5[1] & UN & $\mathrm{C}$ & $\mathrm{J}$ & 38.5 & 8.7 & 2007-2011 (5) & 07/06/2007-13/06/2007 \\
\hline PHD5[2] & UN & $\mathrm{C}$ & $\mathrm{J}$ & 7.7 & 4.1 & $2013(1)$ & 23/06/2011-22/04/2013 \\
\hline PHD6[1] & M & $\mathrm{C}$ & $\mathrm{A}$ & 46.2 & 13.9 & $2008-2015(6)$ & 06/09/2007-31/08/2008 \\
\hline PHD9[1] & $\mathrm{F}$ & $\mathrm{C}$ & A & 7.7 & 4.1 & $2007-2017(4)$ & 06/06/2006-27/06/2007 \\
\hline PHD9[2] & UN & $\mathrm{C}$ & $\mathrm{J}$ & 23.1 & 2.9 & 2011-2016 (3) & 15/06/2010-06/2011 \\
\hline PHD9[3] & UN & $\mathrm{C}$ & $\mathrm{C}$ & 15.4 & 5.2 & 2015-2016 (2) & $20 / 07 / 2015$ \\
\hline PHD9[1][1] & UN & $\mathrm{C}$ & $\mathrm{C}$ & 23.1 & 1.7 & 2015-2017 (2) & $26 / 07 / 2015$ \\
\hline PHD10[1] & $\mathrm{M}$ & $\mathrm{C}$ & $\mathrm{A}$ & 76.9 & 33.1 & 2005-2017 (10) & $19 / 06 / 2005-22 / 06 / 2005$ \\
\hline PHD10[2] & UN & $\mathrm{C}$ & $\mathrm{J}$ & 30.8 & 3.5 & $2009-2015(4)$ & $18 / 06 / 2009$ \\
\hline PHD10[3] & UN & $\mathrm{C}$ & $\mathrm{C}$ & 30.7 & 8.1 & 2014-2017 (4) & $20 / 05 / 2013-09 / 04 / 2014$ \\
\hline
\end{tabular}

was calculated for 5 females and was $3.5 \pm 1.6 \mathrm{yr}$ (SD), ranging from 2 (for PHD4) to 7 yr (for PHD3), although it was observed to be between 2 and 4 yr for 4 females.

\subsection{Weaning period}

The weaning period was calculated based on 8 interbirth intervals for 11 calves with a known birth date within $1 \mathrm{yr}$, while for the others a range period was established (Fig. 1). The mean weaning age was $3.23 \pm 0.61 \mathrm{yr}(\mathrm{SD})$, ranging from 2 to $4 \mathrm{yr}$, but 1 calf (PHD5[1]) may have been weaned as late as its fifth birthday.

\subsection{Postweaning associations}

The postweaning period was estimated for 9 calves which had clear permanent marks before the end of the weaning period, allowing us to follow the complete history of each individual (Fig. 1). Specifically, it was possible to keep track until adulthood ( $>6 \mathrm{yr}$ ) for 3 calves, i.e. 2 males (PHD6[1] and PHD10[1]) and 1 female (PHD9[1]), that were still alive at the end of the project, showing clear site fidelity to the area through several recapture photographs. We were only able to keep track until the juvenile stage $(<6 \mathrm{yr})$ for the other 6 calves of unknown sex (PHD3[2], PHD4[1], PHD4[3], PHD5[1], PHD9[2], and PHD10 [2]), as a result of premature death or migration to other areas, or in cases when they were still juveniles at the end of the project. From the postweaning period, the time of residence in the maternal group was estimated to range from 4 (for PHD4[1]) to $\geq 10 \mathrm{yr}$ (for PHD9[1]), but it was observed to be $\geq 6$ yr for 5 calves (Fig. 1).

\subsection{Age of first reproduction}

We were able to document the reproductive trend of female PHD9[1] in detail. This individual was focally followed from its birth to adult age, and its first pregnancy was recorded at the age of $7.5 \mathrm{yr}$ (Table 1). The ages of first reproduction of the remaining 8 calves which had clear permanent marks before the end of the weaning period remain unknown.

\subsection{Calf mortality}

The number of calves which survived to weaning age $(<6 \mathrm{yr})$ over the $13 \mathrm{yr}$ of the study was also estimated for each female, resulting in $12.5 \%$ mortality by age 1 ( 2 calves); 2 other calves 
PHD3
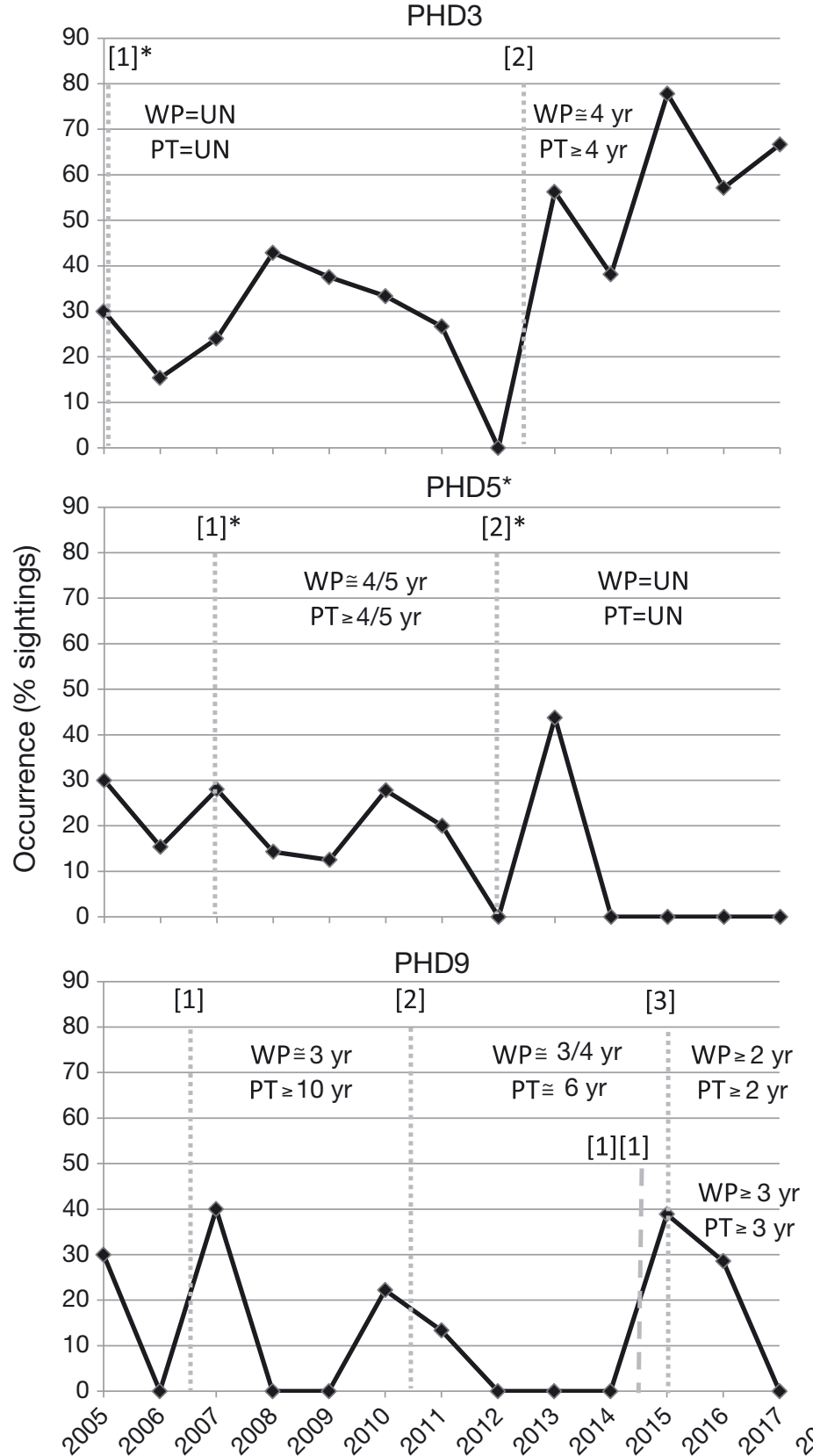

PHD4
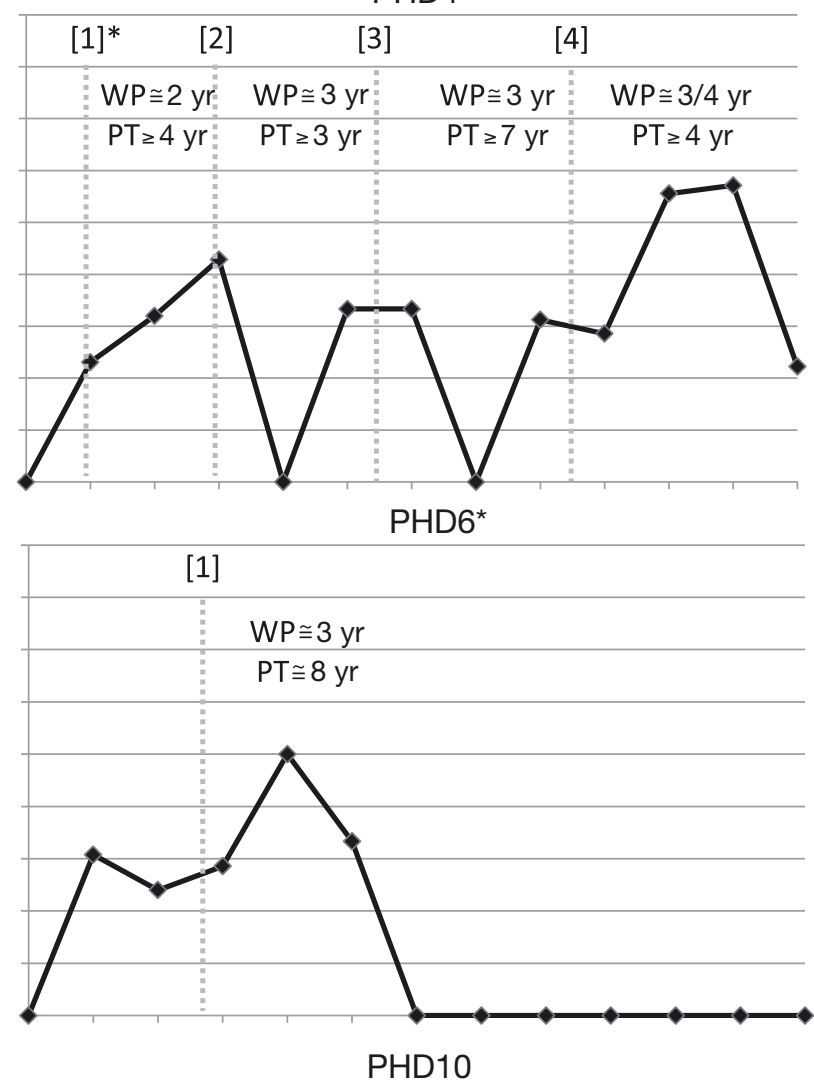

[1]

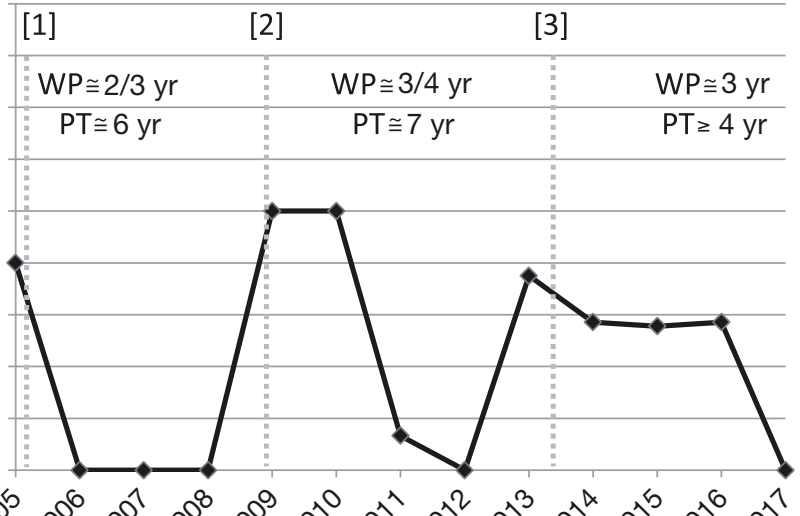

Fig. 1. Occurrence (\% of sightings) of adult reproductive female bottlenose dolphins for each year of study with the birth year of calves [n] (marked by vertical dotted lines; extra gray dashed line represent the offspring of the offspring, [1][1]). Asterisks $\left({ }^{*}\right)$ indicate individuals that were not sighted at the end of the study; WP: weaning period; PT: permanence time in maternal group; UN: unknown

(PHD4[1] and PHD5[1]) died as juveniles (age 46 yr) (Table 2).

\subsection{Female association pattern}

The score plot of the main principal components (Factors 1 and 2) calculated for the HWI showed the association pattern among females and calves/ juveniles with known/unknown mothers (Fig. 2). Two well-distinguished clusters were identified in the plot (Fig. 2): Cluster 1 included 3 females, and Cluster 2 included 5 females. However, the number of calves was not significantly related to the HWI of the mother $\left(\mathrm{R}^{2}=0.07, \mathrm{p}>0.05\right)$ (Table 1). 


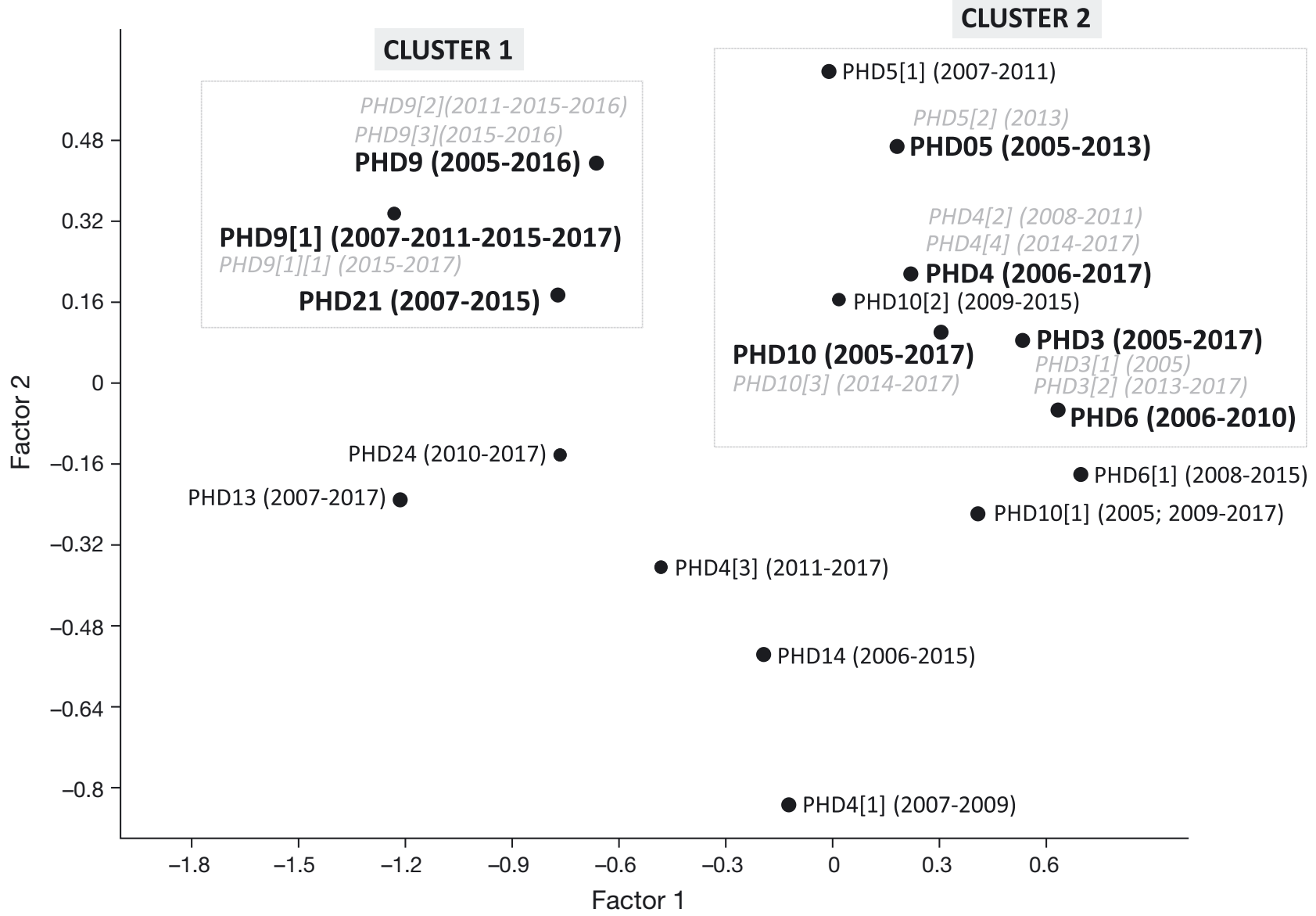

Fig. 2. Main principal components (Factors 1 and 2) calculated for the half-weight index (HWI), showing the association patterns among female bottlenose dolphins (in bold) and juveniles/calves (plain text) with the known mother. Three more juveniles with unknown mothers (PHD13, PHD14, PHD24) were also included to identify potential correlations with other dolphins. For each individual, the ID code and the years of first and last sighting are also indicated in the plot. Grey text indicates

calves/juveniles with known mothers that were not included in the analysis, as they were sighted fewer than 6 times

\section{DISCUSSION}

Reproduction of bottlenose dolphins in their natural environment has been extensively investigated in the scientific literature (Wells 2000, Steiner \& Bossley 2008, Rossi et al. 2017), showing a reproductive trend that may consistently vary among different populations resident in the study area (Haase \& Schneider 2001, Henderson et al. 2014, Fruet et al. 2015) and other populations (Brough et al. 2016, Cheney et al. 2019). However, very few data are available on the reproductive output of Mediterranean bottlenose dolphin populations, where flexible social organization, opportunistic diet, and behaviour may allow them to endure some of the effects of overfishing and habitat degradation (Bearzi et al. 2009, Gnone et al. 2011). In this study, long-term photo-ID data (Blasi \& Boitani 2014, Blasi et al. 2015, Leone et al. 2019) allowed the estimation of important reproductive parameters in bottlenose dolphins living in one Mediterranean area.

\subsection{Female productivity, group size, and association patterns}

In this study, only a few females were clearly associated with 1 or more calves during the study period and consequently were classified as reproductive. Moreover, the population could not be maintained by the 16 calves born in 7 years. The number of calves per female was highly variable, ranging from 1 to 4 , and suggested that reproductive success might be related to several factors, as already found in other bottlenose dolphin populations (Kellar et al. 2017, Robinson et al. 2017, Baker et al. 2018). Many studies 
have shown that female bottlenose dolphins may play an important role in the formation and maintenance of the community social arrangement and conservation of the population (Mann et al. 2000, Blasi \& Boitani 2014, Krzyszczyk et al. 2017). Our results have shown that females have significantly more preferred associates and favour larger groups compared with males (Blasi \& Boitani 2012, 2014, Blasi et al. 2015). Groups of bottlenose dolphins with calves were previously found to be significantly larger than those without calves (Hubard et al. 2004, Blasi \& Boitani 2012, 2014), and in this study the number of calves produced was influenced by the mean maternal group size. The trend of finding calves in larger groups suggests that larger group size may benefit mother-calf pairs (Schaffar-Delaney 2004, Gibson \& Mann 2008, Robinson et al. 2017); however, in this study, the number of calves per female was not significantly related to the strength of the associations of the mother. In Sarasota Bay, Florida (USA), Wells (1991a) showed that survivorship of bottlenose dolphin calves was related to group size. The functions of dolphin groups are numerous (Connor et al. 2000), and larger aggregations could be advantageous for female bottlenose dolphins and their calves in many different ways, including for the protection from predators or conspecifics (Corkeron et al. 1987, Cockcroft et al. 1989) and defence against sexual coercion and infanticide by males (Hrdy 1979, Patterson et al. 1998, Fearnbach et al. 2012). Living in large groups may decrease the risk of predation through increased vigilance (Evans 1987, Alcock 1998, Fellner 2000). Moreover, larger groups may also benefit mother-calf pairs by increasing foraging efficiency, and consequently fertility and productivity, as the location of food resources is facilitated by collaboration among individuals through increased alertness and surveillance. Finally, larger groups may provide increased predation ability (Connor et al. 2000, Fellner 2000) and more opportunity for social learning (Norris \& Dohl 1980, Johnson \& Norris 1986, Wells 1991b). As a result of the high vulnerability of newborn calves and the high energy costs incurred by lactating females, the different advantages of group living appear to be of primary importance for the survival of calves and are likely to explain why newborn dolphins are found in larger groups.

We found that some females disappeared from the study area before giving birth to a new calf. The time interval when a female leaves the study area after giving birth can be used as an index to understand if the individual considers the habitat safe for rearing the calf. In Shark Bay (Australia), Smolker et al.
(1992) noted that after the conception of calves, female bottlenose dolphins remained in their natal area and continued to associate with their mothers. In addition, with the birth of their first calf, females in Sarasota Bay returned to their maternal group (Wells et al. 1987). In our study, some females may have left the study area temporarily to give birth in safer areas (Wells et al. 1987). Fluctuations in the annual residence of females with calves returning to the study area after a segregation period suggest that females may temporarily separate from other females.

\subsection{Birth period}

It is already known that female bottlenose dolphins may coordinate births and, in the Aeolian Archipelago, the birth period takes place during summer, particularly from June to July. Warm water might influence birth seasonality, since it is known to be thermally more efficient for both the calf and the mother (Mann et al. 2000). Firstly, warm water results in greater food availability, which favours seasonal births. Consequently, the food intake of females can be maximized during mid-lactation when nutritional stress is likely to be greatest (Oftedal 1997). Secondly, during the warmest months, the energy demand on lactating females is reduced and less energy is required by the newborn to regulate body temperature (Wells et al. 1987). Seasonality as found in our investigation has also been documented in other studies (Urian et al. 1996, Thayer et al. 2003, Henderson et al. 2014). For example, the calving period of bottlenose dolphins from the southwestern Atlantic Ocean is associated with warmer surface waters (Fruet et al. 2015). In contrast, seasonality was not found in Portugal, where births are registered year-round (Dos Santos \& Lacerda 1987), and a relationship was not found in populations off Florida and Texas (Urian et al. 1996). Local environmental conditions are thought to have an important influence on the seasonality of reproduction (Urian et al. 1996, Tezanos Pinto 2009).

\subsection{First reproduction}

The age of first pregnancy was recorded to be $7.5 \mathrm{yr}$, which is within the ranges reported for other bottlenose dolphin populations (Fruet et al. 2015, Robinson et al. 2017, Kemper et al. 2019). In captivity, a bottlenose dolphin female typically begins to be reproductive at $7-10 \mathrm{yr}$, but may also begin earlier, 
between 5 and 7 yr (Schroeder 1990). In Sarasota (Wells et al. 1987), multiple births were recorded by females between 6 and $7 \mathrm{yr}$ old, in populations where sexual maturity is reached at about 5-12 yr (Tolley et al. 1995). Along the central Atlantic coast, females become sexually mature between 7 and $13 \mathrm{yr}$ (Mead \& Potter 1990). On the other hand, the average sexual maturity of females in South African waters is reached around 9-11 yr (Wells \& Scott 1999). During the first reproduction, females are considered to be young, and consequently, the first calves recorded (Mitcheson 2008) are considered to be more vulnerable to predators. Moreover, young females may not be large or fat enough to be able to nurse a growing calf (Mann et al. 2000). However, in this study, not enough data were available to establish if first-time mothers are more likely to lose their first calf than more experienced mothers (CluttonBrock 1988).

\subsection{Interbirth interval}

The interbirth interval in this study was most commonly between 2 and $7 \mathrm{yr}$, with several females having intervals between 2 and 4 yr. Variability in interbirth intervals can be potentially attributed to several factors, including female age and body mass, year of first reproduction, previous number of calves, calf loss, and weaning period (Mann et al. 2000, Mitcheson 2008, Fruet et al. 2015). Few studies have reported an interbirth interval of $<3 \mathrm{yr}$ for a surviving calf; one study reported an interbirth interval of $3 \mathrm{yr}$ for bottlenose dolphins in Brazil (Fruet et al. 2015), whereas intervals of about $3-5$ yr were found to be more common, e.g. in bottlenose dolphins from Sarasota, which had an interbirth interval of 4 yr (Wells \& Scott 1990). The mean interbirth interval of bottlenose dolphins was $5.3 \mathrm{yr}$ in Doubtful Sound, New Zealand (Henderson et al. 2014), $3.8 \mathrm{yr}$ in Scotland (Mitcheson 2008), and 4.1 yr in Shark Bay, Australia (Mann et al. 2000).

\subsection{Calf mortality}

In our study, calf mortality by age 1 was particularly high $(12.5 \%)$, and 2 other juveniles also disappeared $1 \mathrm{yr}$ or more after weaning and were presumed dead. There may be some underestimation of mortality in young calves, given that some calves likely died before being sighted (Tezanos-Pinto et al. 2015). As our data derive from multiple sightings of mother-calf pairs during the weaning period, we cannot exclude a potentially high level of uncertainty in the determination of whether a calf survived, was successfully weaned and became independent from its mother, or whether a calf died, and a new calf was born before the end of the calving period. The death of a calf in the first year can lower the mean calving interval (Perrin \& Reilly 1984, Cockcroft \& Ross 1990, Bearzi et al. 1997), resulting in a lower mean interbirth interval. The greatest mortality risk occurs within the first months (Mann et al. 2000), which may lead to the mother becoming pregnant again in the year immediately following the death of a juvenile. Furthermore, a calf was assumed to have died if the mother was resighted without the calf upon 2 consecutive encounters (Steiner \& Bossley 2008). The causes of calf mortality are largely unknown in this area. Shark attacks and infanticide are rare in the Mediterranean (Bianucci et al. 2002), but possible causes of death could be associated with changes in diet, age, or malnutrition of the mother due to the low concentrations of prey in the area (Mann et al. 2000, Blasi \& Boitani 2014, Rossi et al. 2017). In Shark Bay, foraging success by the mother is a determining factor in the survival of the calf (Mann et al. 2000). If malnutrition due to insufficient food resources is not the direct cause of calf mortality, other factors likely affect calf survival, including lesions from fishing gear or competition with the artisanal fishery (Blasi \& Boitani 2012, Blasi \& Boitani 2014).

\subsection{Weaning period}

Findings from our study suggest that weaning can last between 2 and $4 \mathrm{yr}$ in bottlenose dolphins from the Aeolian Archipelago, with a mean weaning age of $3.23 \mathrm{yr}_{\text {; }}$ however, 1 calf may have been weaned as late as its fifth birthday, due to its exclusive association with the mother when a new calf was born. Although nursing or swimming in infant position are more reliable indicators for the estimation of the weaning period, an exclusive association pattern with the mother can also be used (Mann et al. 2000). Accordingly, our data show that calves nurse, at least occasionally, for the entire period of infant position swimming, typically $2-4 \mathrm{yr}$, and occasionally up to $5 \mathrm{yr}$. These periods concur with previous estimates of minimum weaning age at $18-20$ mo in other bottlenose dolphin populations (Smolker et al. 1992, Wells \& Scott 1999). As the separation between mother and calf tends to occur before the birth of the next calf (Mann et al. 2000, Wells 2000, Fruet et al. 2015), the 
mean interbirth interval may at least roughly coincide with the time of weaning in these bottlenose dolphin populations.

\subsection{Postweaning associations}

In bottlenose dolphin populations, mother-calf relationships may extend beyond weaning, and calves are likely to remain with their mothers for any length of time (Shane et al. 1986, Scott et al. 1990, Bearzi et al. 1997, Grellier et al. 2003). In this study, it was possible to keep track of calves (until they reached juvenile/adult stages) that had clear permanent marks on the dorsal fin before the end of the weaning period. For these dolphins, the postweaning period lasted from 4-10 yr, but it was more than $6 \mathrm{yr}$ for 5 calves. These long periods of dependency on the mother stress the importance of mother-calf relationships for the development of calves in this population (Grellier et al. 2003). Few studies provide information on postweaning associations in bottlenose dolphins, especially in the Mediterranean Sea, but there is strong evidence that mother-calf associations lasting several years may be related to the benefits derived from these associations (Van Schaik 1989, Gibson \& Mann 2008, Krzyszczyk et. al 2017), such as for foraging or defence from predators/conspecifics (Krzyszczyk et. al 2017). After birth, the early interactions with mothers teach calves important social/ behavioural skills, which will then be extended to a wider social context involving different participants (Makecha 2005). During that time, mothers will increase the chances of survival of their calves by transmitting vital information including food distribution, foraging strategies, predator avoidance, recognition of threats, and patterns of social interactions (Wells et al. 1987, Grellier et al. 2003). These social aspects of calf development are as necessary as motor coordination to gain independence (Wells et al. 1987).

\section{CONCLUSIONS}

Our results provide important information on female reproductive output in a Mediterranean bottlenose dolphin population. These data and previous results highlight the need to implement urgent conservation actions to protect this threatened bottlenose dolphin population. The incorporation of these findings into population viability analyses could help in the design of conservation initiatives, thereby con- tributing to the growth of this population. The need for a larger data set is important for future investigations to understand the primary mechanisms underlying the development and maintenance of femalecalf associations. Of particular interest will be to determine if the low reproductive output is due to calf mortality and/or to female condition, such as fertility and/or malnutrition.

Acknowledgements. We thank all colleagues involved in this project: Dr. Giusy Bonanno Ferraro, Dr. Valentina Caserta, Dr. Carolina Melodia, Dr. Agata Irene Di Paola, and Andrea Benedetto Leone. We thank Dr. Perla Salzeri for English revisions. We also thank the many volunteers and students of Filicudi WildLife Conservation who assisted during the dolphin-monitoring sessions.

\section{LITERATURE CITED}

Alcock J (1998) Animal behavior: an evolutionary approach, $6^{\text {th }}$ edn. Sinauer Associates, Sunderland, MA

Altmann J (1974) Observational study of behaviour: sampling methods. Behaviour 49:227-267

Ansmann IC, Parra GJ, Chilvers BL, Lanyon JM (2012) Dolphins restructure social system after reduction of commercial fisheries. Anim Behav 84:575-581

Baker I, O'Brien J, McHugh K, Berrow S (2018) Female reproductive parameters and population demographics of bottlenose dolphins (Tursiops truncatus) in the Shannon Estuary, Ireland. Mar Biol 165:15

* Bearzi G, Notarbartolo di Sciara G, Politi E (1997) Social ecology of bottlenose dolphins in the Kvarneric (Northern Adriatic Sea). Mar Mamm Sci 13:650-668

Bearzi G, Azzellino A, Politi E, Costa M, Bastianini M (2008) Influence of seasonal forcing on habitat use by bottlenose dolphins Tursiops truncatus in the northern Adriatic Sea. Ocean Sci J 43:175

Bearzi G, Fortuna CM, Reeves RR (2009) Ecology and conservation of common bottlenose dolphins Tursiops truncatus in the Mediterranean Sea. Mammal Rev 39: 92-123

Bëjder L, Fletcher D, Bräger S (1998) A method for testing association patterns of social animals. Anim Behav 56: 719-725

* Bezamat C, Castilho PV, Simões-Lopes PC, Ingram SN, Daura-Jorge FG (2020) Reproductive parameters and factors influencing calf survival of bottlenose dolphins that engage in a unique foraging cooperation with fishermen. Mar Biol 167:5

Bianucci G, Bisconti M, Landini W, Storai T, Zuffa M, Giuliani S, Mojetta A (2002) Trophic interaction between white shark, Carcharodon carcharias, and cetaceans: a comparison between Pliocene and recent data from Central Mediterranean Sea. In: Vacchi M, La Mesa G, Serena F, Séret B (eds) Proc $4^{\text {th }}$ European Elasmobranch Association. ICRAM, ARPAT \& SFI, Livorno, p 33-48

Blasi MF, Boitani L (2012) Modelling fine-scale distribution of the bottlenose dolphin Tursiops truncatus using physiographic features on Filicudi (southern Thyrrenian [sic] Sea, Italy). Endang Species Res 17:269-288 
Blasi MF, Boitani L (2014) Complex social structure of an endangered population of bottlenose dolphins (Tursiops truncatus) in the Aeolian Archipelago (Italy). PLOS ONE 9:e114849

Blasi MF, Giuliani A, Boitani L (2015) Influence of trammel nets on the behaviour and spatial distribution of bottlenose dolphins (Tursiops truncatus) in the Aeolian Archipelago, Southern Italy. Aquat Mamm 41:295-310

* Bräger S, Würsig B, Acevedo A, Henningsen T (1994) Association patterns of bottlenose dolphins (Tursiops truncatus) in Galveston Bay, Texas. J Mammal 75:431-437

* Brough TE, Henderson S, Guerra M, Dawson SM (2016) Factors influencing heterogeneity in female reproductive success in a Critically Endangered population of bottlenose dolphins. Endang Species Res 29:255-270

Cairns SJ, Schwager SJ (1987) A comparison of association indices. Anim Behav 35:1454-1469

Caswell H (2001) Matrix population models. Construction, analysis and interpretation, $2^{\text {nd }}$ edn. Sinauer Associates, Sunderland, MA

Cheney BJ, Thompson PM, Cordes LS (2019) Increasing trends in fecundity and calf survival of bottlenose dolphins in a marine protected area. Sci Rep 9:1-9

Clutton-Brock TH (1988) Reproductive success: studies of individual variation in contrasting breeding systems. University of Chicago Press, Chicago, IL

Cockcroft VG, Ross GJB (1990) Age, growth, and reproduction of bottlenose dolphins Tursiops truncatus from the east coast of southern Africa. Fish Bull 88:289-302

Cockcroft VG, Cliff G, Ross GJB (1989) Shark predation on Indian Ocean bottlenose dolphins (Tursiops truncatus) off Natal, South Africa. S Afr J Zool 24:305-310

Connor RC, Wells RS, Mann J, Read AJ (2000) The bottlenose dolphin: social relationships in a fission-fusion society. In: Mann J, Connor RC, Tyack PL, Whitehead H (eds) Cetacean societies: field studies of dolphins and whales. University of Chicago Press, Chicago, IL, p 91-126

Corkeron PJ, Morris RJ, Bryden MM (1987) Interactions between bottlenose dolphins and sharks in Moreton Bay, Queensland. Aquat Mamm 13:109-113

Dos Santos ME, Lacerda M (1987) Preliminary observations of the bottlenose dolphins (Tursiops truncatus) in the Sado estuary (Portugal). Aquat Mamm 13:65-80

Evans PGH (1987) The natural history of whales and dolphins. Christopher Helm, London

Fearnbach H, Durban J, Parsons K, Claridge D (2012) Seasonality of calving and predation risk in bottlenose dolphins on Little Bahama Bank. Mar Mamm Sci 28: 402-411

Fellner W (2000) Synchrony between a mother-calf pair of bottlenose dolphins (Tursiops truncatus). BSc thesis, University of South Florida, Tampa, FL

Foroughirad V, Mann J (2013) Long-term impacts of fish provisioning on the behavior and survival of wild bottlenose dolphins. Biol Conserv 160:242-249

Fruet PF, Genoves RC, Möller LM, Botta S, Secchi ER (2015) Using mark-recapture and stranding data to estimate reproductive traits in female bottlenose dolphins (Tursiops truncatus) of the Southwestern Atlantic Ocean. Mar Biol 162:661-673

Fujiwara M, Caswell H (2001) Demography of the endangered North Atlantic right whale. Nature 414:537-541

Gibson QA, Mann J (2008) Early social development in wild bottlenose dolphins: sex differences, individual variation and maternal influence. Anim Behav 76:375-387
Gnone $G$, Bellingeri M, Dhermain F, Dupraz F and others (2011) Distribution, abundance, and movements of the bottlenose dolphin (Tursiops truncatus) in the Pelagos Sanctuary MPA (north-west Mediterranean Sea). Aquat Conserv 21:372-388

Gol'din P, Gladilina E (2015) Small dolphins in a small sea: age, growth and life-history aspects of the Black Sea common bottlenose dolphin Tursiops truncatus. Aquat Biol 23:159-166

Grellier K (2000) Reproductive biology of female bottlenose dolphins (Tursiops truncatus) using the Moray Firth, Scotland. PhD thesis, University of Aberdeen

*Gellier K, Hammond PS, Wilson B, Sanders-Reed CA, Thompson PM (2003) Use of photo-identification data to quantify mother-calf association patterns in bottlenose dolphins. Can J Zool 81:1421-1427

Haase PA, Schneider K (2001) Birth demographics of bottlenose dolphins, Tursiops truncatus, in Doubtful Sound, Fiordland, New Zealand-preliminary findings. NZ J Mar Freshw Res 35:675-680

*Hammer Ø, Harper DAT, Ryan PD (2001) PAST: Paleontological statistics software package for education and data analysis. Palaeontol Electron 4:9, http://palaeo-electronica .org/2001_1/past/issue1_01.htm

Hammond PS, Mizroch SA, Donovan GF (1990) (eds) Individual recognition of cetaceans: use of photo-identification and other techniques to estimate population parameters. Rep Int Whal Commn (Special Issue 12). International Whaling Commission, Cambridge

* Henderson SD, Dawson SM, Currey JC, Lusseau D, Schneider K (2014) Reproduction, birth seasonality, and calf survival of bottlenose dolphins in Doubtful Sound, New Zealand. Mar Mamm Sci 30:1067-1080

*Hrdy SB (1979) Infanticide among animals: a review, classification, and examination of the implications for the reproductive strategies of females. Ethol Sociobiol 1:13-40

*Hubard CW, Maze-Foley K, Mullin KD, Schroeder WW (2004) Seasonal abundance and site fidelity of bottlenose dolphins (Tursiops truncatus) in Mississippi Sound. Aquat Mamm 30:299-310

Johnson CM, Norris KS (1986) Delphinid social organization and social behavior. In: Schusterman RJ, Thomas JA, Wood FG (eds) Dolphin cognition and behavior: a comparative approach. Lawrence Erlbaum Associates, Hillsdale, NJ, p 335-346

Karniski C, Krzyszczyk E, Mann J (2018) Senescence impacts reproduction and maternal investment in bottlenose dolphins. Proc R Soc B 285:20181123

Kasuya T, Izumisawa Y, Komyo Y, Ishino Y, Maejima Y (1997) Life history parameters of bottlenose dolphins off Japan. IBI Rep 7:71-107

Kellar NM, Speakman TR, Smith CR, Lane SM and others (2017) Low reproductive success rates of common bottlenose dolphins Tursiops truncatus in the northern Gulf of Mexico following the Deepwater Horizon disaster (2010-2015). Endang Species Res 33:143-158

Kemper C, Talamonti M, Bossley M, Steiner A (2019) Sexual maturity and estimated fecundity in female Indo-Pacific bottlenose dolphins (Tursiops aduncus) from South Australia: combining field observations and postmortem results. Mar Mamm Sci 35:40-57

Krzyszczyk E, Patterson EM, Stanton MA, Mann J (2017) The transition to independence: sex differences in social and behavioural development of wild bottlenose dolphins. Anim Behav 129:43-59 
Leone AB, Bonanno Ferraro G, Boitani L, Blasi MF (2019) Skin marks in bottlenose dolphins (Tursiops truncatus) interacting with artisanal fishery in the central Mediterranean Sea. PLOS ONE 14:e0211767

Makecha RN (2005) The ontogeny of social play in bottlenose dolphins (Tursiops truncatus) calves. Doctoral dissertation, University of Southern Mississippi, Hattiesburg, MS

Mann J (1999) Behavioural sampling methods for cetaceans: a review and critique. Mar Mamm Sci 15:102-122

Mann J, Smuts BB (1998) Natal attraction: allomaternal care and mother-infant separations in wild bottlenose dolphins. Anim Behav 55:1097-1113

Mann J, Connor RC, Barre LM, Heithaus MR (2000) Female reproductive success in bottlenose dolphins (Tursiops sp.): life history, habitat, provisioning, and group-size effects. Behav Ecol 11:210-219

Mead JG, Potter CW (1990) Natural history of bottlenose dolphins along the central Atlantic coast of the United States. In: Leatherwood S, Reeves RR (eds) The bottlenose dolphin. Academic Press, New York, NY, p 165-195

Mitcheson H (2008) Inter-birth interval estimation for a population of bottlenose dolphins (Tursiops truncatus): accounting for the effects of individual variations and changes over time. MSc thesis, University of St. Andrews

Norris KS, Dohl TP (1980) The structure and function of cetacean schools. In: Herman LM (ed) Cetacean behavior. John Wiley \& Sons, New York, NY, p 211-261

Oftedal OT (1997) Lactation in whales and dolphins: evidence of divergence between baleen- and toothedspecies. J Mammary Gland Biol Neoplasia 2:205-230

Patterson IAP, Reid RJ, Wilson B, Grellier K, Ross HM, Thompson PM (1998) Evidence for infanticide in bottlenose dolphins: an explanation for violent interactions with harbour porpoises? Proc R Soc B 265:1167-1170

Perrin WF, Reilly SB (1984) Reproductive parameters of dolphins and small whales of the family Delphinidae. Rep Int Whal Comm (Spec Issue) 6:97-134

Read AJ, Wells RS, Hohn AA, Scott MD (1993) Patterns of growth in wild bottlenose dolphins, Tursiops truncatus. J Zool (Lond) 231:107-123

Reeves R, Notarbartolo di Sciara G (eds) (2006) The status and distribution of cetaceans in the Black Sea and Mediterranean Sea. Workshop Report. The World Conservation Union (IUCN), Centre for Mediterranean Cooperation, Malaga

Robinson KP, Sim TMC, Culloch RM, Bean TS and others (2017) Female reproductive success and calf survival in a North Sea coastal bottlenose dolphin (Tursiops truncatus) population. PLOS ONE 12:e0185000

Rossi A, Scordamaglia E, Bellingeri M, Gnone G and others (2017) Demography of the bottlenose dolphin Tursiops truncatus (Mammalia: Delphinidae) in the Eastern Ligurian Sea (NW Mediterranean): quantification of female reproductive parameters. Euro Zool J 84:294-302

Schaffar-Delaney A (2004) Female reproductive strategies and mother-calf relationships of common dolphins (Delphinus delphis) in the Hauraki Gulf, New Zealand. MSc thesis, Massey University, Albany

Schroeder JP (1990) Breeding bottlenose dolphins in captivity. In: Leatherwood S, Reeves RR (eds) The bottlenose dolphin. Academic Press, New York, NY, p 435-446

Scott MD, Wells RS, Irvine AB (1990) A long-term study of bottlenose dolphins on the West Coast of Florida. In:
Leatherwood S, Reeves RR (eds) The bottlenose dolphin. Academic Press, New York, NY, p 235-244

Shane SH (1990) Behavior and ecology of the bottlenose dolphins at Sanibel Island, Florida. In: Leatherwood S, Reeves RR (eds) The bottlenose dolphin. Academic Press, New York, NY, p 245-265

* Shane SH, Wells RS, Würsig B (1986) Ecology, behaviour and social organization of the bottlenose dolphin: a review. Mar Mamm Sci 2:34-63

Smolker RA, Richards AF, Connor RC, Pepper JW (1992) Sex differences in patterns of association among Indian Ocean bottlenose dolphins. Behaviour 123:38-69

Steiner A, Bossley M (2008) Some reproductive parameters of an estuarine population of Indo-Pacific bottlenose dolphins (Tursiops aduncus). Aquat Mamm 34:84-92

Tavolga MC (1966) Behavior of the bottlenose dolphin (Tursiops truncatus): social interactions in a captive colony. In: Norris K (ed) Whales, dolphins, and porpoises. University of California Press, Berkeley, CA, p 718-730

Tezanos-Pinto G (2009) Population structure, abundance and reproductive parameters of bottlenose dolphins (Tursiops truncatus) in the Bay of Islands (Northland, New Zealand). PhD thesis, University of Auckland

* Tezanos-Pinto G, Constantine R, Mourão F, Berghan J, Scott Baker C (2015) High calf mortality in bottlenose dolphins in the Bay of Islands, New Zealand, a local unit in decline. Mar Mamm Sci 31:540-559

* Thayer VG, Read AJ, Friedlaender AS, Colby DR and others (2003) Reproductive seasonality of western Atlantic bottlenose dolphins off North Carolina, USA. Mar Mamm Sci 19:617-629

* Tolley KA, Read AJ, Wells RS, Urian KW, Scott MD, Irvine AB, Hohn AA (1995) Sexual dimorphism in wild bottlenose dolphins (Tursiops truncatus) from Sarasota, Florida. J Mammal 76:1190-1198

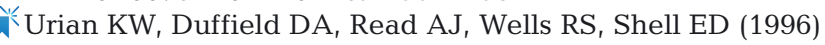
Seasonality of reproduction in bottlenose dolphins, Tursiops truncatus. J Mammal 77:394-403

Van Schaik CP (1989) The ecology of social relationships amongst female primates. In: Standen V, Foley RA (eds) Comparative socioecology. The behavioural ecology of humans and other mammals. Blackwell, Oxford, p 195-218

Wells RS (1991a) The role of long-term study in understanding the social structure of a bottlenose community. In: Pryor K, Norris KS (eds) Dolphin societies, discoveries and puzzles. University of California Press, Oakland, CA, p 199-226

Wells RS (1991b) Bringing up baby. Nat Hist 100:56-62

Wells RS (2000) Reproduction in wild bottlenose dolphins: overview of patterns observed during a long-term study. In: Duffield D, Robeck T (eds) Report of the bottlenose dolphins reproduction workshop, June 3-6, Silver Springs, MD, p 57-74

Wells RS, Scott MD (1990) Estimating bottlenose dolphin population parameters from individual identification and capture release techniques. Rep Int Whal Comm (Spec Issue) 12:407-415

Wells RS, Scott MD (1999) Bottlenose dolphin Tursiops truncatus (Montagu, 1821). In: Ridgway SH, Harrison RJ (eds) Handbook of marine mammals: the second book of dolphins and porpoises. Academic Press, New York, NY, p 137-182

Wells RS, Scott MD, Irvine AB (1987) The social structure of free ranging bottlenose dolphins. In: Genoways $\mathrm{H}$ 
(eds) Current mammalogy, Vol 1. Springer, Boston, MA, p 247-305

Whitehead H (1996) Babysitting, dive synchrony and indications of allopaternal care in sperm whales. Behav Ecol Sociobiol 38:237-244

Whitehead H, Dufault S (1999) Techniques for analyzing vertebrate social structure using identified individuals: review and recommendations. Adv Stud Behav 28:33-74

Würsig B, Jefferson TA (1990) Methods of photo-identification for small cetaceans. In: Hammond PS, Mizroch SA,

Editorial responsibility: Victor Benno Meyer-Rochow, Oulu, Finland
Donovan GP (eds) Individual recognition of cetaceans: use of photo-identification and other techniques to estimate population parameters. Rep Int Whal Comm (Spec Issue) 12:43-52

* Würsig B, Würsig M (1977) The photographic determination of group size, composition and stability of coastal porpoises (Tursiops truncatus). Science 198:755-756

Würsig B, Würsig M (1979) Behaviour and ecology of the bottlenose dolphin, Tursiops truncatus, in the South Atlantic. Fish Bull 77:399-412

Submitted: March 12, 2020; Accepted: July 8, 2020

Proofs received from author(s): September 1, 2020 